\title{
LA PRAXIS EDUCATIVA COMO ACONTECIMIENTO ÉTICO: UNA APROXIMACIÓN A LAS PROPUESTAS DE MÉLICH Y SAVATER
}

THE EDUCATIONAL PRAXIS AS ETHICAL SUCCESS: AN APPROACH TO MÉLICH AND SAVATER'S PROPOSALS 



\title{
LA PRAXIS EDUCATIVA COMO ACONTECIMIENTO ÉTICO: UNA APROXIMACIÓN A LAS PROPUESTAS DE MÉLICH Y SAVATER
}

\section{THE EDUCATIONAL PRAXIS AS ETHICAL SUCCESS: AN APPROACH TO MÉLICH AND SAVATER'S PROPOSALS}

\author{
Roger Vilain
}

\begin{abstract}
Palabras clave: educación, ética, moral, acción educativa.
\end{abstract}
Key words: education, ethics, moral, educational action.

\section{RESUMEN}

En este trabajo pretendemos indagar la propuesta ético-educativa de Joan Carles Mélich (1994) y sus posibles vínculos con las ideas de Fernando Savater $(1999,2004)$. Creemos que el ámbito de la educación y la ética son dos planos que en Mélich y Savater permanecen inextricables, de modo que esta, como filosofía moral que hurga los valores de un nuevo modo de vivir en sociedad, im- plica la irrupción de un acontecimiento educativo que marca de forma indeleble al educando. Así, el individuo o "yo" debe construirse a partir de la relación mutua con un "tú" reconocido como ontológicamente igual, al punto de que la comunidad resultante, es decir la sociedad, se deriva de la interacción permanente entre sujetos que imponen mutuamente responsabilidades, respetos, dignidades 
(Kant, 2002), que desembocan en una concepción de la educación en tanto revelación de la condición humana. Se trata de una investigación de tipo descriptivo-explicativo cuyo enfoque epistemológico es intuitivo-introspectivo.

\section{ABSTRACT}

This research focuses on inquiry about the educational-ethical thought of Joan Carles Mélich (1994) and possible links with the thought of Fernando Savater (1999-2004). We believe that education and ethics are two linked dimensions Mélich and Savater, so this, such as moral philosophy that digs the values of a new way of living in society, implies the irruption of an educational event that influences the learner. Thus, the subject of "me" must be constructed from the mu- tual relationship with a the other or "you" both recognized as ontologically equal, to the point that the resulting community or society, is derived from the permanent interaction between subjects who impose mutually responsibilities, respect and dignity (KANT, 2002). The conception of education reveals the human condition. The research is descriptive-explanatory whose epistemological approach is intuitive and introspective.

\section{LA PRAXIS EDUCATIVA COMO ACONTECIMIENTO ÉTICO: UNA APROXIMACIÓN A LAS PROPUESTAS DE MÈLICH Y SAVATER'1.}

\section{I}

En todos los aspectos del acontecer humano la ética desempeña un rol preponderante. Sin esta, las actividades que llevamos a cabo seguramente carecerían del asidero filosófico que posiblemente las justificara, o cuando menos, las pensara en tanto actividades más o menos trascendentes. Como la ética es una actitud, una reflexión que echa mano de la libertad individual para analizar situaciones, sopesar, criticar, balancear posibles hipótesis y posturas para luego pronunciarse, el ámbi-

${ }^{1}$ Los discursos educativos sobre los que se asienta este trabajo corresponden a las propuestas de Joan Carles Mélich (1994) y Fernando Savater (1999, 2004), reportadas en las respectivas referencias bibliográficas. 
to de la ética es también el ámbito del individuo ${ }^{2}$.

La reflexión ética supone la puesta en marcha de un hacer que atañe a cada uno de nosotros y que no habría que confundir, pongamos por caso, con la reflexión estrictamente política, necesaria para mantener la paz social y la convivencia civilizada entre humanos. La ética, como sugiere Savater, "no puede ser sustituta de la reflexión política o de la reflexión jurídica, o de otras cuestiones igualmente imprescindibles" (Savater: 1999,9)

Ella supone un acto de reflexión realizado por un individuo que, sustentado en su condición de hombre libre, es capaz de completarlo. Así, quien ejerce un oficio cualquiera (el oficio de la política solo es uno de ellos) será capaz de pensar libremente en relación con su quehacer en un momento determinado. El plano de la ética está presente cuando dejamos el estamento profesional, el oficio en tanto el oficio, y accedemos a un peldaño sobre el que vislumbramos lo que hacemos, y lo cuestionamos marcando posición, emitiendo juicios, cambiando de opinión (o reafirmándola) en relación con ciertos aspectos que nos interesan, para con la responsabilidad del momento tomar entonces decisiones argumentadas.

Si la educación pasa por el manejo de ciertos aprendizajes en lo atinente, por ejemplo, a lo social, la reflexión ética rebasa este estadio e implica, cobra para sí, el fuero interno de los individuos, básicamente porque el ámbito de la ética es uno que implica a cada particular forma de valorar y conjeturar sobre lo que llevamos a cabo o hacemos, ahora tomando en cuenta el ejercicio educativo. Nuevamente leamos a Savater:

¿Qué queremos decir cuando nos preguntamos cuál es el eje, el núcleo central de la valoración ética que queremos que una democracia resguarde? Creo que, en primer lugar, la ética es siempre de la persona. La ética es aquello que se preocupa de lo irrepetible y frágil que es el ser humano, de cada uno de los seres humanos. La ética no es una relación instrumental, porque no es una relación que se toma estadísticamente, globalmente, sino que es una relación que intenta mantener el tú a tú,

\footnotetext{
${ }^{2} \mathrm{Al}$ hacer referencia a la noción de ética es necesario conocer la distinción entre esta y su equivalente en el lenguaje común, no filosófico: la moral. Tal diferenciación es fundamental llevarla a cabo y tenerla clara, pues ambos términos se utilizan en filosofía para designar dos tipos de saberes. En palabras de Adela Cortina (2005: 42): "La moral es un tipo de saber encaminado a forjar un buen carácter, que ha formado y forma parte de la vida cotidiana de las personas y de los pueblos. Por eso podemos decir que no la han inventado los filósofos, mientras que la ética, por el contrario, sería filosofía moral, es decir, una reflexión sobre la moral cotidiana hecha por filósofos, que utilizan para ello la jerga propia de la filosofía".
} 
el cara a cara, el mantenerse frente a la mirada del otro, frente al reconocimiento del otro. (Savater: 1999, 12).

No podemos vivir, notémoslo, dándole la espalda a la ética, del mismo modo que no podemos vivir al margen de la educación. A través de aquella intentamos asir los medios para alcanzar vivir la vida que deseamos, esa que proyectamos para la sociedad y para nosotros como individuos. Sobre la base de comprender, de asimilar el rol fundamental de la ética en el ejercicio educativo, y luego de haber considerado nociones fundamentales de ética en filosofía, en nuestro trabajo reflexionaremos acerca del discurso ${ }^{3}$ ético-educativo de Joan Carles Mélich y Fernando Savater como acontecimiento ético.

\section{II}

El hecho educativo supone la existencia de diversos elementos que lo conforman. Es necesaria la presen- cia de alguien que educa y alguien que pretende educarse, así como múltiples factores (el contexto social, la rutina familiar, el ambiente, por ejemplo) que intervienen con mayor o menor intensidad en el proceso. Semejante cuestión presenta elevados picos de complejidad (consideremos aquí las características particulares de los protagonistas o la coherencia en los planteamientos y objetivos de enseñanza), por lo que, entre otras razones, la reflexión acerca de la actividad educativa es tan antigua como variada. Son muchos los horizontes y puntos de vista desarrollados a través del tiempo a propósito de la educación como fenómeno social. En nuestro caso intentaremos aproximarnos al discurso educativo de Joan Carles Mélich y Fernando Savater con la intención de evidenciar, en la medida de lo posible, sus particularidades y relaciones, su sentido, así como la visión humanística que desde sus haceres en tanto pensadores arrojan a modo de propuestas.

\footnotetext{
${ }^{3}$ Partiremos de las ideas de Renkema (1999) al referirnos al término "discurso". Para identificar a un discurso como tal (aquí, obviamente, los discursos educativos de Joan Carles Mélich y Fernando Savater) es imperativa la existencia de cohesión, lo cual implica un entramado de palabras, de oraciones, de texto, bien estructurado, así como la observancia de coherencia. Es necesario asimismo que el emisor intente comunicar algo, es decir, que se dé una intencionalidad discursiva. Además, todo discurso deberá poseer informatividad y aceptabilidad, lo que en otras palabras consiste en que tal discurso sea portador de información verificable y sea esta de igual modo aceptada, desde la perspectiva gramatical, por los diferentes interlocutores. Es de vital importancia que haya adaptación entre el discurso producido y la situación (situacionalidad), lo cual exige la ineludible consideración del contexto en el que se desarrolla todo proceso comunicativo. Por último, Renkema considera la intertextualidad, la existencia de vínculos evidenciables entre un determinado texto discursivo y otros. Para profundizar más al respecto, cfr.: Renkema, Jean (1999) Introducción a los estudios sobre el discurso. Barcelona: Gedisa.
} 
Es preciso comenzar diciendo que la idea ético-educativa de Mélich parte de una noción desarrollada primeramente por Edmund Husserl, esta es, la de "mundo de la vida cotidiana". Desde nuestra cotidianidad, desde el día a día que nos sumerge en sus dolores o alegrías, construimos el marco intersubjetivo que será el escenario donde desarrollamos la existencia. Y es precisamente esa existencia, comienza a decirnos Mélich, la que estamos condenados a labrar desde el yo, desde la experiencia particular, hasta dar con un tú que asimismo nos busca y requiere de nosotros para, entre ambos, definir un entrecruzamiento educativo, un aprendizaje mutuo, una ética común que eleve tanto a la educación como a la ética propiamente dicha a niveles de acontecimiento trascendental, es decir, a estratos que marquen al individuo, lo transformen, hagan de él un ciudadano capaz de vislumbrar al otro al tiempo que se vislumbra a sí mismo. Por eso, el mismo Mélich nos dice que "el concepto husserliano de mundo de la vida (lebenswelt) se convierte en punto de apoyo de una posible filosofía de la educación en la vida cotidiana4" (Mélich: 1994, 18). La vida de todos los días vista entonces como el eje primordial sobre el que se va a enarbolar una nueva manera de vivir.
Así, tal horizonte espacial y temporal que cubre y envuelve los acontecimientos que se desarrollan en la cotidianidad, de modo espontáneo, azaroso, irreflexivo, es en efecto el mundo de la vida cotidiana que constituye el punto de partida de las observaciones de nuestro autor. De semejante mundo de la vida cotidiana se desprenden entonces varias acciones (acción social, pedagógica, moral y educativa), que darán cuerpo al momento neurálgico en las tesis de Mélich, no otro que la formación mediada por una acción educativa cuyo sustrato fundamental es una concepción ética que incluye al otro para la realización del yo y viceversa.

Inmersos ya en ese mundo de la vida cotidiana, las acciones mencionadas se dan, se entrecruzan, abanderadas por la acción educativa, esa que teje el dibujo, el perfil teleológico del individuo a formar. Como toda filosofía de la educación, la de Mélich no es en modo alguno inocente: existe aquí una búsqueda consciente y una manera de estar en el mundo y de relacionarse con él. Solo la acción educativa, arrastrando al resto de las acciones que conforman el entramado ético y educativo que teoriza nuestro filósofo, resulta en la idea perseguida de hombre (el hombre en función del ser-

\footnotetext{
${ }^{4}$ Las ideas de Husserl en relación con el "mundo de la vida" pueden encontrarse en: Husserl, Edmund (1985). Investigaciones lógicas. Madrid: Alianza y en Husserl, Edmund (1975). Ideas II. México: Fondo de Cultura Económica.
} 
con-el-otro). Es por esto que manifiesta lo siguiente:

"La educación, en el ámbito de la cotidianidad, es una acción social, pero una acción social con características propias, entre las que destaca la moralidad. El hecho moral no es condición suficiente para comprender la interacción educativa, pero sí condición necesaria". (Mélich: 1994, 18).

Hay aquí algunos elementos que comentar. El primero de ellos es la realidad planteada como hecho educativo amalgamado con una irrenunciable acción social. No hay educación sin los otros, sin una comunidad. "Educar es, en esencia, lanzarse hacia el otro" (Mélich: 1994, 18), de modo que el diálogo intersubjetivo se hace presente, se evidencia y patentiza como un sine qua non. El segundo elemento implica la presencia de la moralidad, pero no considerada desde una perspectiva que la hace apéndice de un proceso (el proceso educativo), sino parte fundamental de este, "condición necesaria" para que él ocurra, según palabras del autor. No en balde debe ser así, pues la moral que erige Mélich es, tengámoslo presente, un modo de-ser-con-los otros. El otro se presenta al yo como un tú que lo encara, lo necesita, y tal dupla construye un nosotros sustentado en el reconocimiento de la alteridad como valor clave social.

A propósito de esto, Fernando Savater plantea en El valor de educar (2004), sus posiciones relativas a lo que supone es educar, pero educar con base en el propio yo y en otro, un tú que tenemos enfrente y que nos interpela siempre en disposición al diálogo creador, única manera de desarrollar lo que el mismo Savater llama "neotenia o plasticidad juvenil". Entonces sostiene que "la posibilidad de ser humano solo se realiza efectivamente por medio de los demás, de los semejantes" (Savater: 2004: 25). Hay aquí, qué duda cabe, un paralelismo con la concepción de Mélich que salta a la vista, en esencia por la constatación del hecho moral que desde el yo y el tú crea una propuesta ética distinta, afianzada en la noción del respeto a la singularidad de cada quien, en plena relación humana con el otro. Es imposible, según ambas concepciones, desvincular la educación de la ética por la razón sencilla de que al hacerlo se desvirtúa el modelo humano que se pretende. Mélich llega a manifestarlo así:

De entre los seres vivos, el antrhopos es un ser no especializado. Es lo que ontológicamente se expresaría diciendo (...) que es una 'nada de ser' $(\text { Sartre) })^{5}$. La realidad humana es un

\footnotetext{
${ }^{5}$ En el existencialismo sartreano el hombre debe hacerse a sí mismo. No tenemos esencia o naturaleza
} 
ente que necesita del proceso educativo para constituirse. No hay antrhopos al margen de la paideia. (Mélich: 1994, 74).

Y para constituirse, la acción educativa -como punta de lanza de la acción social, pedagógica y moral- resulta de un valor inestimable en su propuesta.

La acción social, mediante la que todo individuo puede modelar su conducta considerando siempre la interpretación de la conducta de los demás (ser-sí-mismo, ser-tú, ser-con y ser-en-elmundo) se abraza con la acción pedagógica, relativa a las diversas interacciones del yo con el medio ambiente, con el entorno en general, para fraguar así el alter ego a partir de la subjetividad de los demás. Mélich nos expresa su punto de vista al respecto afirmándolo sin ambages: "La interioridad y la mismidad se construyen frente a frente, a través de los ojos del otro, a través de su mirada" (Mélich: 1994, 16. Resaltado nuestro). Lo anterior se ausculta, se hace asimismo evidente en Fernando Savater cuando sostiene que "el destino de cada humano no es la cultura, ni siquiera estrictamente la sociedad en cuanto institución, sino los semejantes" (Savater: 2004, 31). Hay, entonces, una mismidad que es tal en la medida en que somos-con-los-otros.

Ser humanos supone la creación de un rostro particular, es decir, un sercon-el-otro, tal como hemos venido afirmando. Este es el derivado ontológico que observamos en la propuesta de Joan Carles Mélich. El ser con el otro lleva aparejada la madurez ética, si es que pudiéramos Ilamarla así, susceptible de vislumbrar un mundo en el que estamos incrustados, conformándolo, siendo parte activa de él, echando mano del reconocimiento de la alteridad. Ahí está la clave del asunto. El reconocimiento de la dignidad humana, el reconocimiento de cada quien (siguiendo la tradición occidental kantiana ${ }^{6}$ ) porque nos necesitamos para ser, para elaborar nada menos que el yo. Sin el otro, sin el tú, la presencia de mi propio yo es poco menos que imposible. Según Sartre, estamos condenados al no individualismo, cuando menos el no individualismo que margina y nos transforma en seres ensimismados (la irrupción y permanencia del nefasto en-sí, que nos cosifica) para quienes humana alguna, es preciso desarrollarla vivencialmente. "La existencia precede a la esencia", será el desideratum sartreano por antonomasia. Una "nada de ser" debe entonces labrarse un proyecto y un destino humano. Para profundizar al respecto, cfr.: Sartre, Jean Paul (1980). El existencialismo es un humanismo. Barcelona: Orbis.

${ }^{6}$ En la tradición occidental ilustrada Kant nos enseña que la persona humana es digna porque conforma un fin en sí misma, no un instrumento o medio para acceder a ciertos fines posteriores. Cfr.: Kant, Immanuel. (2002). Crítica de la razón práctica. Salamanca: Sígueme. 
lo único importante es el terreno de lo particular. De acuerdo a tal razonamiento, consideremos lo que en ese sentido observamos en Mélich y Savater:

"La educación, pues, puede caracterizarse en una primera reducción como una antropogénesis (...) La paideia es un trascendental, pero no un trascendental gnoseológico sino ontológico, esto es, condición de posibilidad de la existencia." (Mèlich: 1994, 74).

Y además, según Popper, continúa diciéndonos que "la verdad de existir se aprehende intersubjetivamente, de ahí que consideremos la intersubjetividad como un rasgo fundamental, entre otros, del conocimiento (...)" (Mélich: 1994, 29). Lo anterior hace pensar, como de alguna manera lo hemos sugerido ya, no solo en una educación que otorga a la ética un lugar predominante en su razón de ser. Si fuese así estaríamos ante un postulado educativo más. Por el contrario, nos parece que el pensamiento de Mèlich cobra visos de notoriedad, de alta reflexión acerca de una realidad, en educación, que se extiende más allá, que cala hondo, cobrando importancia capital y que es urgente profundizar, internalizar, poner en práctica. Educación y ética manifiestan aquí un todo inextricable. Solo podremos hacer de este mundo, de nosotros, de la sociedad y de la cultura un lugar más habitable y, en fin, mejor para todos, si somos capaces de incorporar al otro en nuestros planes, si aprendemos a mirar al otro como estrictamente necesario para nuestro proyecto humano (alcanzar la condición de seres humanos gracias a la educabilidad que nos distingue). Leamos lo que en relación con lo anterior sostiene Savater en El valor de educar:

"El hecho de enseñar a nuestros semejantes y de aprender de nuestros semejantes es más importante para el establecimiento de nuestra humanidad que cualquiera de los conocimientos concretos que así se perpetúan o transmiten. De las cosas podemos aprender efectos o modos de funcionamiento, tal como el chimpancé despierto -tras diversos tanteos- atina a empalmar dos cañas para alcanzar el racimo de plátanos que pende del techo; pero

del comercio intersubjetivo con los semejantes aprendemos significados. La vida humana consiste en habitar un mundo en el que las cosas no solo son lo que son sino que también significan; pero lo más humano de todo es comprender que, si bien lo que sea la realidad no depende de nosotros, lo que la realidad significa sí resulta competencia, problema y en 
cierta medida opción nuestra." (Savater: 2004, 31. Resaltado nuestro).

La acción moral, entonces, se da mientras las acciones sociales y pedagógicas ocurren. No son fenómenos ubicados en compartimentos estancos o mutuamente excluyentes. Por el contrario, dan cuerpo a un hacer sistemático que teje una red de relaciones cuyo punto de fuga es teleológicamente un fin muy bien determinado: la idea de hombre basada, hay que repetirlo una vez más, en el ser-con-el-otro. Para esto, la acción moral pasa por convertirse en un modo, una manera de ser-con-losotros. Existen valores que superan lo estrictamente societario, es decir, irrumpe la moral justamente al otorgarle al otro un valor absoluto que lo hace único, igual a mí, que lo dignifica y pone enfrente como alguien visible, con rostro propio, capaz de relacionarse conmigo (y yo con él dialécticamente) de igual a igual. El otro no será ya un objeto o elemento cosificable sino una presencia que marca improntas de responsabilidad, de respeto, de dignidad y de humanidad. La mirada ética pasa así por la relación dual entre el tú y el yo que luego explota en una comunidad de seres aptos para compartir su humanidad. Mélich se refiere justo a esto cuando argumenta que
En el entorno físico, en el mundo, el cuerpo se me da como un objeto entre otros. Pero el desenvolvimiento de la corporeidad me abre una nueva dimensión antropológica (...) Miro mi mano, puedo medir sus dimensiones. La acaricio. Noto su textura. La actitud natural inmediata y cotidiana me la descubre como objeto del mundo, pero mi mano no se reduce a ser algo de suyo. (Mélich: 1994, 78).

La mano como objeto según el ojo escrutador del mundo en la cotidianidad, pero la idéntica mano como hecho trascendental, no cosificado, si la observamos unida a un ente que ha construido un yo, ha reconocido un tú y ha cultivado una conciencia ética particular. Savater, por su parte, da cuenta de la necesaria educación descosificadora, reveladora del yo como absoluto, también en función de la existencia de los demás. No otra cosa implica el hecho de manifestar que "la llave para entrar en el jardín simbólico de los significados siempre tenemos que pedírsela a nuestros semejantes" (Savater: 2004, 32), lo cual supone la fragua mancomunada de una realidad significativa, plena de símbolos, de cultura, en la que podemos entendernos y desplegar así el hecho de pensarnos y pensar a quienes serán nuestros interlocutores en la tarea impostergable de vivir. En tal sentido guarda Savater la 
esperanza que el humano pueda pensar lo que piensa, esto es, dar prioridad al carácter autorreflexivo a propósito de nuestra vida en común. Nuestra realidad y las realidades ajenas en constante diálogo creador. Una ética de la mirada sobre sí mismo y sobre el tú con quienes vivimos en sociedad. "El sentido de la vida humana", continúa expresando el filósofo,

No es un monólogo sino que proviene del intercambio de sentidos, de la polifonía coral. Antes que nada, la educación es la revelación de los demás, de la condición humana como un concierto de complicidades irremediables. (Savater: 2004, 35).

Así pues, la acción educativa relativa al pensamiento de Mélich forma parte de una acción social cuyo estamento moral le es intrínseco y por supuesto irrenunciable. El yo impone sus requerimientos humano-ontológicos, su necesidad de ser, a través del tú, lo que posibilita la creación de nuestra idiosincrasia a partir de las mutuas relaciones entre todos. Somos seres aptos para compartir, nótese, no la mera esfera de cosas materiales sino (he aquí buena parte del sentido de la educación en Merlich y en Savater) el ámbito mismo de la fragua de nuestra humanidad a través de la creación del propio ser. Para esto, necesitamos siempre de los otros.

El sentido de la educación en ambos pensadores comienza a evidenciarse. Es posible notar entonces la exigencia de educar para la forja de un hombre entregado a la tarea de saber que vive para sí y para un colectivo. El rostro del ser individual adquiere la fisonomía ontológica del ser-con-los-otros, resultado de una mutua construcción de significados que nos unen en tanto individuos pertenecientes a la gran cultura de lo humano. Así, "se educa para", siempre desde una ética del sujeto en contraposición al objeto, se trasciende el individualismo cosificador y adquirimos valores universales, idealizables, compartibles. La educación, en Mélich y en Savater, no constituye mero sustantivo abstracto o accidente improvisado. Por el contrario, implica una tarea de síntesis social-educativa donde el enfoque ético ocurre por la fragua de lo humano en función de las mutuas relaciones, del diálogo, es decir, en la mirada que soy capaz de sostener cuando el otro está ahí y también me observa ontológicamente. "Antropológicamente hablando no hay yo sin tú", nos confirma Mélich, de modo que "la acción social es la acción significativa, es una llamada al sentido, y todo sentido implica una conciencia" (Mélich: 1994, 86. Resaltado nuestro). 
Creemos que al hurgar en el sentido de la educación en Mélich y Savater estamos obligados -como intentamos haberlo hecho a lo largo de este trabajo- a considerar la ética como ámbito fundamental de la praxis educativa. La educación como acontecimiento ético, nada más y nada menos. La "conciencia", referida por Mélich, parte de la necesidad de vislumbrar que existe un tú, tan igual al yo, que posee una realidad, que vive $y$ es portador de derechos y deberes, todo ubicable exactamente en el mismo nivel en el que creo encontrar al yo que voy labrando con la ayuda de terceros. Es, a fin de cuentas, un imperativo categórico sin el cual se banaliza toda intención ética-educativa. Semejante reconocimiento supone el acceso a la condición humana del que parte una manera distinta de concebirnos y concebir a los demás, sobre la base de relaciones intersubjetivas. De igual modo, cuando trata aspectos relativos a la otredad, la alteridad o nuestros semejantes, Savater lo expresa con claridad:

"Tenemos que aprender a leer sus mentes, lo cual no equivale simplemente a la destreza estratégica de prevenir sus reacciones y adelantarnos a ellas para condicionarlas en nuestro beneficio, sino que implica ante todo atribuirles estados mentales como los nuestros y de los que depende la propia calidad de los nuestros. Lo cual implica considerarles sujetos y no meros objetos; protagonistas de su vida y no meras comparsas vacías de la nuestra." (Savater: 2004, 34).

Tanto para Mélich como para Savater la educación es, sobre todo, toma de conciencia de la condición humana, de nuestra racionalidad, pero también de que somos personas inevitablemente éticas, habitantes de un universo simbólico construido artificialmente por nosotros (cultura). Somos, así, partícipes corresponsables de lo mutuamente significativo.

Quizás como metáfora literaria de lo anterior, el novelista turco Orhan Pamuk en La maleta de mi padre (2007) da cuenta del yo y del tú expresados a través de la escritura y la lectura. Nos ha parecido un interesante y hermoso ejemplo de cómo la teoría, la reflexión, el pensamiento filosófico educativo de Joan Carles Mélich y Fernando Savater, desplegado en sus respectivos ensayos, hasta cierto punto florece con vitalidad sorprendente en un texto y en un quehacer (el del novelista y el de quienes lo leen), ejemplificando cómo es posible hallar vías para la acción social y educativa que atraviesan las ideas de los filósofos considerados aquí. Se trata de una actividad que, desde la perspectiva pedagógica, podría usarse con la intención de propiciar en los educandos las 
experiencias necesarias para la construcción de la conciencia ética y la noción de sujeto presentes en las consideraciones tanto de Mélich como de Savater. Leamos lo que Pamuk nos confiesa:

"Los maravillosos mecanismos de la novela sirven para ofrecer a la humanidad entera nuestra historia como si fuera la de otro (...) Gracias a las buenas novelas intentamos alterar los límites, primero de los demás, y luego los nuestros. Los otros se convierten en 'nosotros' y nosotros en 'los otros' (...) La historia de la novela también podría escribirse como la historia de la forma en que nos liberamos y nos transformamos mediante la imaginación al ocupar el lugar de otro (...) En ocasiones trato de traer ante mi mirada, uno por uno y en la geografía correspondiente, a los lectores que están leyendo una novela, retirados en un rincón, sentados en una butaca. Entonces cobran vida miles, decenas de miles de lectores dispersos por ciudades de los cuatro puntos cardinales que al leer un libro imaginan los sueños, los personajes y el universo del autor. Ahora esos lectores, como el mismo autor, están usando su imaginación, están intentando ponerse en el lugar del otro. Esos son los momentos en que se agitan en nuestros corazones la tolerancia, la modestia, la ternura, la compasión y el amor: la buena literatura no apela a nuestro poder de juzgar sino a nuestra capacidad de ponernos en lugar de otros." (Pamuk: 2007, 75-76, 77, 87).

La educación, entonces, como revelación de la condición humana, lo cual conlleva implicaciones que marcan en definitiva a quienes se hacen copartícipes de ella (no otros que los educandos). En tal sentido, presente en el nosotros y justo ante el yo, se encuentra el tú que aparece como noción y, más que como noción, como ser, con idéntica presencia, deberes y derechos a respetar.

El yo sin el otro no puede finalmente constituirse, de modo que el nosotros quedaría entonces suspendido. Existe una conciencia, desarrollada entre otras por la educación formal, que posee intencionalidad evidente. Tal conciencia se encuentra vinculada con cierta voluntad a propósito de la necesidad de educarse, de imbuirse en la condición de ciudadano, de humanizarse cada vez más en función del encuentro con el otro.

Aun cuando lo anterior es verdad, tomando en cuenta el hecho significativo que la disposición para la educación, para la mutua construcción de símbolos culturales descansa sobre la intención, es decir, la de quien educa y la de quien se educa (cuando menos desde el horizonte 
de las instituciones formales), es preciso tener presente que una parte en absoluto desdeñable de los aprendizajes (sociales, por ejemplo), no obedece a la lógica señalada de la intencionalidad sino que se produce y asienta de un modo mucho menos dirigido a partir de una teleología determinada. Esa parte de los aprendizajes a la que hacemos mención ocurre de manera inconsciente y no por ello menos efectiva. El "currículo oculto", presente en las instituciones educativas, ilustra muy bien lo que pretendemos decir. Fluyendo a través de esta otra enseñanza, no dirigida ni intencional, se evidencian actitudes, valores, formas de comportamiento y, en fin, aprendizajes, que marcarán sin duda con profundidad a quien se educa. Relacionada con semejante hecho, corriendo paralela a esos modos de educación extraintencionales, subyace asimismo una ética que debe ser necesariamente considerada al momento de vislumbrar procesos educativos y las vinculaciones entre el yo y el tú para la conformación del nosotros.

Ya para finalizar, en el complejo entramado del universo, la simbología tejida por lo humano, labrada desde el artificio e ingenio que les son inherentes, conforma el ámbito cultural que es siempre compartido. Somos herederos y a la vez creadores del constantemente renovado orden de lo significativo, derivación esta que subyace a nuestra condición de hombres capaces de inventar un mundo cargado de signos e interpretaciones. Una de las implicaciones más urgentes del hecho educativo, partiendo desde el horizonte escudriñado en este artículo, supone entonces vislumbrar a un tú, a un otro, en tanto sujeto ético que dialoga con un yo, en igualdad de condiciones, conformando el nosotros plural, abierto, semánticamente interactivo, base fundamental de una relación entre pares mucho más rica, dinámica y perdurable. Tal es la conclusión generalizadora que desprendemos de las propuestas consideradas a lo largo de estas páginas. Se trata de una ética que subyace al quehacer educativo propiciando un rostro humano sustentado en las relaciones intersubjetivas, en el otro como posibilidad plena de realización del yo. 


\section{REFERENCIAS BIBLIOGRÁFICAS}

Cortina, Adela. (2005). El mundo de los valores. Bogotá: Búho.

Husserl, Edmund. (1975). Ideas II. México: Fondo de Cultura Económica.

(1985). Investigaciones lógicas. Madrid: Alianza.

Kant, Immanuel. (2002). Crítica de la razón práctica. Salamanca: Sígueme.

Mélich, Joan Carles. (1994). Del extraño al cómplice: la educación en la vida cotidiana. Barcelona: Antrhopos.

Pamuk, Orhan. (2007). La maleta de mi padre. Barcelona: Mondadori.

Renkema, Jean. (1999). Introducción a los estudios sobre el discurso. Barcelona: Gedisa.

Sartre, Jean Paul. (1980). El existencialismo es un humanismo. Barcelona: Orbis.

Savater, Fernando. (1999). Ética y ciudadanía. Caracas: Monte Ávila. . (2004). El valor de educar. Barcelona: Ariel. 